\title{
AMADURECIMENTO DE SAPOTI (Manilkara zapota L.) SUBMETIDO AO 1-METILCICLOPROPENO ${ }^{1}$
}

\author{
PATRÍCIA LÍGIA DANTAS DE MORAIS², LUIZ CARLOS DE OLIVEIRA LIMA ${ }^{3}$, \\ RICARDO ELESBÃO ALVES ${ }^{4}$, JOSÉ DONIZETI ALVES ${ }^{3}$, ALESSANDRA DE PAIVA ALVES 5
}

\begin{abstract}
RESUMO - Este trabalho tem como objetivo avaliar o efeito do 1-MCP no controle do amadurecimento de sapoti. Os frutos foram colhidos no estádio de maturação fisiológico (fruto apto para amadurecer separado da planta-mãe), tratados com 0; 300 e $600 \mathrm{~nL} \mathrm{~L}^{-1}$ de 1-MCP por 12 horas em câmaras vedadas a $25 \pm 2^{\circ} \mathrm{C}$ e umidade relativa de $70 \pm 5 \%$. Ao término do tratamento com 1-MCP, os frutos foram armazenados por 23 dias nas mesmas condições de temperatura e umidade. As variáveis analisadas foram: perda de massa fresca, aparência externa, firmeza, cor da polpa, acidez titulável, $\mathrm{pH}$, sólidos solúveis e açúcares solúveis totais. O 1-metilciclopropeno (1-MCP) retarda o amadurecimento e prolonga a vida útil pós-colheita de sapoti. A concentração de $300 \mathrm{~nL} . \mathrm{L}^{-1}$ de 1-MCP apresentou melhores resultados, prolongando a vida útil pós-colheita do sapoti por seis dias.
\end{abstract}

Termos para indexação: etileno, amadurecimento, vida util, pós-colheita

\section{RIPENING OF SAPODILLA (Manilkara zapota L.) SUBMITTED TO 1-METHYLCYCLOPROPENE}

\begin{abstract}
This work aimed to evaluate the effect of different concentrations of 1-MCP on the ripening process of sapodilla. Fruits were harvested at the physiologically mature stage and treated with 0,300 and $600 \mathrm{~nL} \cdot \mathrm{L}^{-1}$ dosages of 1-MCP for 12 hours in hermetically closed chambers at $25 \pm 2{ }^{\circ} \mathrm{C}$ and $70 \pm 5 \%$ R.H..

After the $12 \mathrm{~h} \mathrm{1-MCP}$ treatment, the fruits were stored for 23 days under the same conditions of temperature and humidity. The parameters analyzed for postharvest quality were: weight loss, external appearance, firmness, pulp color, total titrable acidity, total soluble solids and total soluble sugar content. In sapodilla, 1-MCP delays ripening and prolongs the postharvest shelf life and the $300 \mathrm{~nL} . \mathrm{L}^{-1}$ of $1-\mathrm{MCP}$ dosage showed the best results extending the postharvest life of sapodilla in 6 days.
\end{abstract}

Index terms: ethylene, ripening, shelf-life, postharvest.

\section{INTRODUÇÃO}

O sapotizeiro é uma espécie exótica que se adaptou muito bem no Brasil, principalmente na região Nordeste do País. Os seus frutos apresentam sabor e aroma bastante apreciados pelos consumidores, chegando a atingir preços elevados $(\mathrm{R} \$ 4,00 / \mathrm{kg})$ no mercado interno. No Brasil, o maior consumo do sapoti é in natura, mas, em outros países, como no México, este fruto é muito utilizado na indústria para a fabricação de doces, refrescos, conservas, geléias e xaropes (Báez et al., 1997).

A produção do sapotizeiro, geralmente, concentra-se em três meses do ano nos países produtores (Mickelbart, 1996). Porém, resultados de pesquisas desenvolvidas pela Embrapa no Nordeste do Brasil mostraram que a fertirrigação propiciou mudanças na produção do sapotizeiro, tornando-o produtivo durante todo o ano. Este novo cenário tem estimulado novos produtores, sobretudo o pequeno, pois propicia uma renda distribuída durante o ano e um abastecimento constante do mercado (Bandeira et al., 2003).

Apesar da potencialidade do sapotizeiro como frutífera alternativa para a agroindústria nordestina, faltam tecnologias para o manejo e conservação pós-colheita de seus frutos.

A utilização de inibidores da ação do etileno tem sido muito utilizada como um tratamento pós-colheita para aumentar a vida útil de frutos. O 1-metilciclopropeno (1-MCP) é um destes inibidores e têm se destacado pela alta eficiência, não deixando resíduos e tendo sido registrado para utilização em produtos alimentícios (Hamrick, 2001).

O presente trabalho tem como objetivo estudar o efeito do 1MCP no controle do amadurecimento de sapotis.

\section{MATERIAL E MÉTODOS}

Os frutos utilizados neste experimento foram provenientes de plantio comercial, irrigado, localizado na JAISA (Jaguaribe Agroindústria Sociedade Anônima), no Estado do Ceará. A cultivar utilizada foi a Itapirema-31, cujas mudas para instalação do pomar foram obtidas na Empresa Pernambucana de Pesquisa Agropecuária (IPA). O espaçamento das plantas do pomar é de $8,0 \mathrm{~m} \mathrm{x} \mathrm{8,0m,} \mathrm{e} \mathrm{a}$ idade, em torno de nove anos. A colheita dos frutos foi realizada em janeiro de 2004, no período da manhã, para minimizar perdas por transpiração, utilizando-se de tesoura de poda, deixando-se, aproximadamente, $1 \mathrm{~cm}$ de pedicelo. Os sapotis foram colhidos no estádio de maturação fisiológica, observando-se características indicativas da maturação, como idade (seis meses da frutificação), massa máxima (em torno de $200 \mathrm{~g}$ ), formato mais esférico e pouca granulosidade na casca (Araújo Neto et al., 2001; Miranda, 2002). Posteriormente, os frutos foram acondicionados em caixas de plástico, forradas com espuma de poliestireno e transportados para o Laboratório de Fisiologia e Tecnologia Pós-colheita da Embrapa Agroindústria Tropical, em Fortaleza - CE, distante em torno de $200 \mathrm{~km}$ do local de cultivo.

No laboratório, os frutos foram selecionados quanto ao tamanho, grau de maturação, sanidade e ausência de defeitos. Em seguida, foram imersos, por cinco minutos, em emulsão do fungicida Benomil a $1.000 \mathrm{mg} . \mathrm{L}^{-1}$. Um lote de 12 frutos foi analisado no dia da colheita, e os demais frutos foram divididos em 21 lotes (três concentrações e sete tempos de avaliações) e tratados com 0 (controle), 300nL L-1 e $600 \mathrm{~nL} \mathrm{~L}^{-1}$ de $1-\mathrm{MCP}$, por 12 horas, em minicâmaras com volume de 186 litros, vedadas e à temperatura de

\footnotetext{
${ }^{1}$ (Trabalho 16-2006). Recebido: 17-02-2006. Aceito para publicação: 25-08-2006.

${ }^{2}$ Doutora em Fisiologia Vegetal. Bolsista de DCR/FAPERN/CNPq. Universidade Federal Rural do Semi-Árido, CP 137, CEP 59625-900, Mossoró - RN; Email: plmorais@ufersa.edu.br.

${ }_{3}^{3}$ Doutores e professores adjuntos da Universidade Federal de Lavras, CP 3037, CEP 37200-000, Lavras - MG, Brasil. E-mail: lcolima@ufla.br, jdalves@ ufla.br

${ }^{4}$ Doutor em Ciências dos Alimentos. Pesquisador da Embrapa Agroindústria Tropical, CP 3761, CEP 60511-110, Fortaleza - CE, Brasil. E-mail: elesbao@cnpat.embrapa.br

${ }^{5}$ Bolsista de iniciação científica. Universidade Federal de Lavras, CP 3037, CEP 37200-000, Lavras - MG, Brasil. E-mail: alessandraufla@ hotmail.com.
} 
$25 \pm 2^{\circ} \mathrm{C}$ e umidade relativa de $70 \pm 5 \%$. O produto comercial do 1 MCP utilizado foi o Smartfresh®, na formulação em pó, contendo $0,14 \%$ do ingrediente ativo. O produto foi colocado em frasco com septo na tampa para injeção de água deionizada, pois, quando o produto comercial é diluído na água, ocorre liberação do 1-MCP na forma de gás. Depois de colocada a água, o frasco foi introduzido na minicâmara por meio de abertura lateral e esta vedada imediatamente para evitar a perda do gás. Ao término do tratamento, os frutos foram colocados em bandejas de poliestireno expandido, com quatro frutos cada e recobertas com filme de PVC (cloreto de polivinila) com espessura de $12 \mu$, a fim de reduzir a perda de massa e diminuir a desuniformidade de amadurecimento entre os frutos. Mesmo seguindo todos os indicativos do ponto de colheita citado anteriormente, é dificil colher um lote de sapoti com maturação uniforme. Os frutos foram armazenados nas mesmas condições do tratamento $\left(25 \pm 2^{\circ} \mathrm{C}\right.$ e $70 \pm 5 \%$ UR), por 23 dias, e as avaliações, realizadas aos $0 ; 4 ; 8 ; 11 ; 14 ; 17 ; 20$ e 23 dias de armazenamento.

Para avaliação da aparência externa, foi adotada uma escala subjetiva de acordo com Miranda et al. (2002), com algumas alterações. As notas variaram de 1 a 5 , com base na porcentagem dos frutos afetados por incidência de manchas, infecção por fungos e enrugamento: $1=$ ausência de sintomas; $2=1 \%$ a $15 \% ; 3=16 \%$ a $30 \%$; $4=31 \%$ a $45 \%$ e $5=$ mais de $45 \%$ dos frutos afetados. Frutos com notas superiores a 3,0 foram considerados inadequados para comercialização. A perda de massa fresca foi obtida por meio da massa individual dos frutos, no dia da colheita e na data da avaliação, utilizando-se balança semi-analítica. A firmeza foi determinada utilizando-se um texturômetro digital computadorizado da marca Stable Micro Systems, modelo TA.XT2i, equipado com ponteira de $6 \mathrm{~mm}$ de diâmetro. Para a cor da polpa, o fruto foi cortado ao meio, e as leituras, feitas na parte interna de cada metade, utilizando-se de um colorímetro marca Minolta, modelo CR-300, que expressa a cor por meio das variáveis, $\mathrm{L}^{*}$ ou luminosidade, cromaticidade ou intensidade da cor, e ângulo hue, que indica a tonalidade da cor.

As análises químicas foram realizadas após o descongelamento da polpa previamente processada. O processamento da polpa foi feito em um homogeneizador elétrico e, para facilitar esse processo, adicionou-se água destilada em quantidade equivalente ao peso do fruto, resultando em uma diluição $1: 1$, que foi considerada para efeito de cálculo dos resultados. A acidez titulável foi determinada por titulação da amostra com solução de $\mathrm{NaOH}$ a $0,1 \mathrm{M}$ até $\mathrm{pH} 8,1$, conforme metodologia do Instituto Adolfo Lutz (1985). Os teores de sólidos solúveis foram determinados por leitura em refratômetro digital Atago, modelo PR100 Pallete (AOAC, 2002). Os açúcares solúveis totais foram extraídos em etanol $80 \%$ e determinados usando-se a reação com antrona, conforme Yemn \& Willis (1954).

$\mathrm{O}$ experimento foi conduzido em delineamento inteiramente casualizado, sendo os tratamentos dispostos em esquema fatorial $3 \times 8$, correspondente ao controle e duas doses de 1-MCP e oito tempos de armazenamento. Utilizaram-se três repetições com quatro frutos cada. Os resultados das características avaliadas foram submetidos à análise de variância. Quando houve interação significativa dos fatores, procedeu-se à análise de regressão polinomial.

\section{RESULTADOS E DISCUSSÃO}

O tratamento com 1-MCP retardou a senescência do sapoti, pois as notas para aparência externa foram menores para os frutos tratados do que para o controle. Apesar de ter sido realizado tratamento com o fungicida Benomil, antes do armazenamento, ainda houve incidência de fungo do gênero Pestalotiopsis. A aparência externa limitou a vida útil dos frutos-controle em 15 dias e dos tratados com $300 \eta \mathrm{L} \mathrm{L} \mathrm{L}^{-1}$ de 1-MCP em 21 dias; já os frutos tratados com a dose de $600 \eta \mathrm{L} \mathrm{L}^{-1}$ apresentaram vida útil de 20 dias, pois a incidência de fungo foi maior nestes frutos, comprometendo sua aparência externa (Figura 1). Foram considerados inadequados para comercialização os frutos com notas superiores a 3,0. Saltveit (1999) relatou que o etileno influencia na aparência do fruto, pelo fato de este hormônio acelerar o amadurecimento e, conseqüientemente, a senescência. Dessa forma, no presente trabalho, o 1-MCP foi capaz de manter o fruto com uma boa aparência por mais tempo.

A perda de massa apresentou comportamento linear e correlacionou-se positivamente com o tempo de armazenamento. Os frutos tratados com 600 nL.L ${ }^{-1}$ de 1-MCP obtiveram perda de massa ao final do armazenamneto de $8,44 \%$, que foi menor do que o controle, que apresentou 9,35\% de perda de massa. Já os frutos tratados com a dose de $300 \mathrm{~nL} . \mathrm{L}^{-1}$ de 1-MCP apresentaram valores para perda de massa próximos aos obtidos para o controle (Figura 2). Na literatura, o efeito do tratamento com 1-MCP sobre a perda de massa ainda não está bem definido. Existem trabalhos em que o 1MCP permitiu a redução da perda de massa em alguns frutos, tais como o abacate (Jeong et al., 2002). No entanto, também se tem constatado, em alguns casos, como em laranja, que o tratamento com 1-MCP não apresentou nenhum efeito sobre a perda de massa (Porat et al., 1999).

A redução da perda de massa pelo tratamento com 1-MCP pode ser justificada por redução na atividade metabólica do fruto, a qual, geralmente, tem sido constatada em frutos tratados com 1MCP (Cocozza, 2003).

Os valores para perda de massa foram inferiores aos verificados em outros trabalhos com sapotis, armazenados sob atmosfera regular (Araújo Neto et al., 2001). Morais et al. (2004), trabalhando com duas cultivares de sapoti ('BRS-227' e 'BRS-228'), verificaram uma perda de massa que alcançou $22,3 \%$, aos 12 dias de armazenamento, a $26^{\circ} \mathrm{C}$ e $55 \%$ de umidade relativa. Esta perda de massa provocou enrugamento dos frutos, comprometendo a aparência dos mesmos.

A interação entre os fatores tratamento com 1-MCP e tempo de armazenamento foi significativa para a luminosidade ( $\left.\mathrm{L}^{*}\right)$, cromaticidade e ângulo Hue da polpa. O tratamento com 1-MCP foi eficiente em retardar a coloração da polpa dos frutos, independentemente da dose, conforme os resultados obtidos para as três variáveis (Figuras 3A, 3B e 3C).

De acordo com os valores de $\mathrm{L}^{*}$, a polpa escureceu com o amadurecimento, sendo que os tratados com 1-MCP mantiveram a cor da polpa mais clara do que os frutos-controle. Durante o amadurecimento, a cor da polpa do sapoti alterou-se de creme para marrom, o que pode ser verificado pelo aumento da cromaticidade e redução do ângulo hue. Os frutos tratados com 1-MCP apresentaram coloração marrom, com tonalidade amarelo-vívida, com os frutos do controle apresentando-se marrons, com tonalidade vermelha e pouco intensa.

O tratamento com 1-MCP não promoveu diferenças significativas na acidez titulável dos frutos, no entanto houve significância na interação entre o tratamento com 1-MCP e o tempo de armazenamento (Figura 4). A acidez titulável dos frutos-controle diminuiu até o $11^{\circ}$ dia, aumentando em seguida até o final do experimento. Nos frutos tratados com 1-MCP, observou-se que a redução na acidez continuou até o $20^{\circ}$ dia, com aumento no $23^{\circ}$ dia. Este acréscimo pode ser justificado pela ocorrência de fermentação provocada pelo início da senescência. Os sapotis tratados com 1MCP mantiveram o teor de acidez maior que o controle até o $14^{\circ}$ dia, indicando retardo na produção de ácidos e, conseqüentemente, no amadurecimento (Figura 4). Cocozza (2003) também observou retardo na diminuição da acidez em manga tratada com 1-MCP, sendo a dose de $500 \mathrm{~nL} \mathrm{~L}^{-1}$ mais efetiva do que a de $100 \mathrm{~nL} \mathrm{~L}^{-1}$.

Não houve efeito significativo dos fatores estudados para os teores de sólidos solúveis (SS) e açúcares solúveis totais (AST), cujos valores médios obtidos foram $21,45^{\circ}$ Brix e $14,57 \%$, respectivamente. 


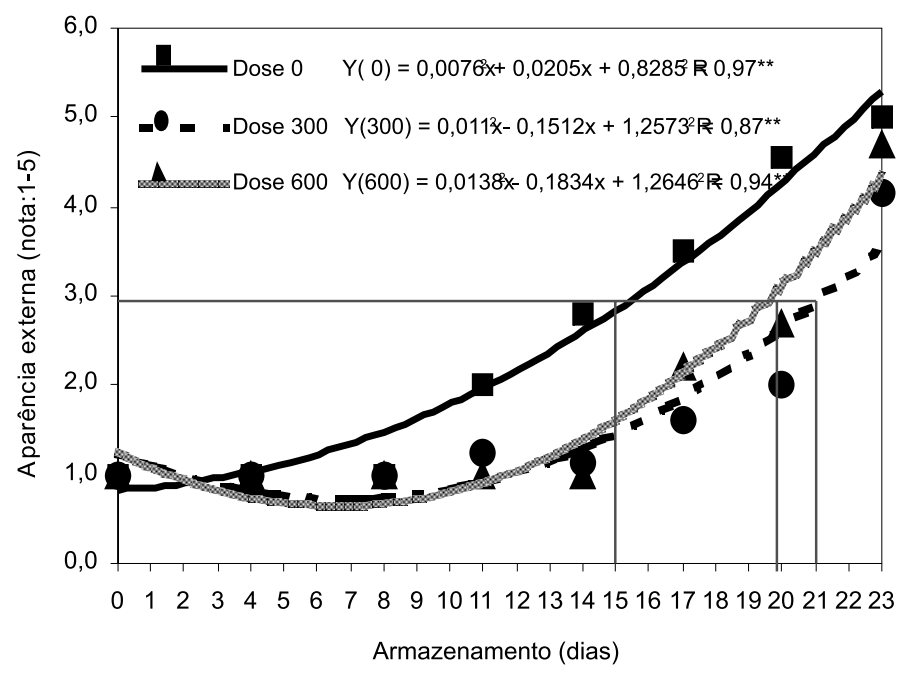

FIGURA 1 - Aparência externa de sapotis após tratamento com 0; 300 e $600 \mathrm{~nL} \mathrm{~L}^{-1}$ de 1 -MCP e armazenados a $25^{\circ} \mathrm{Ce} 70 \%$ UR.

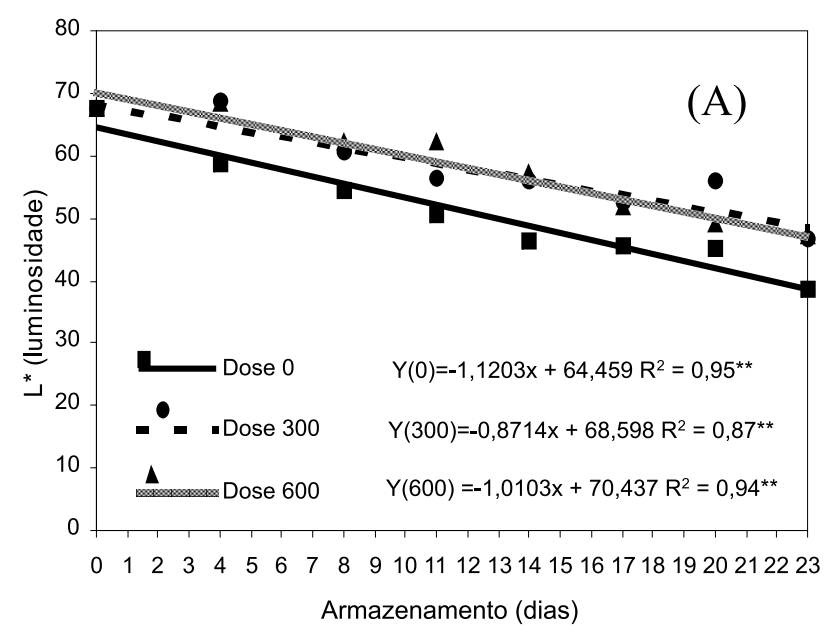

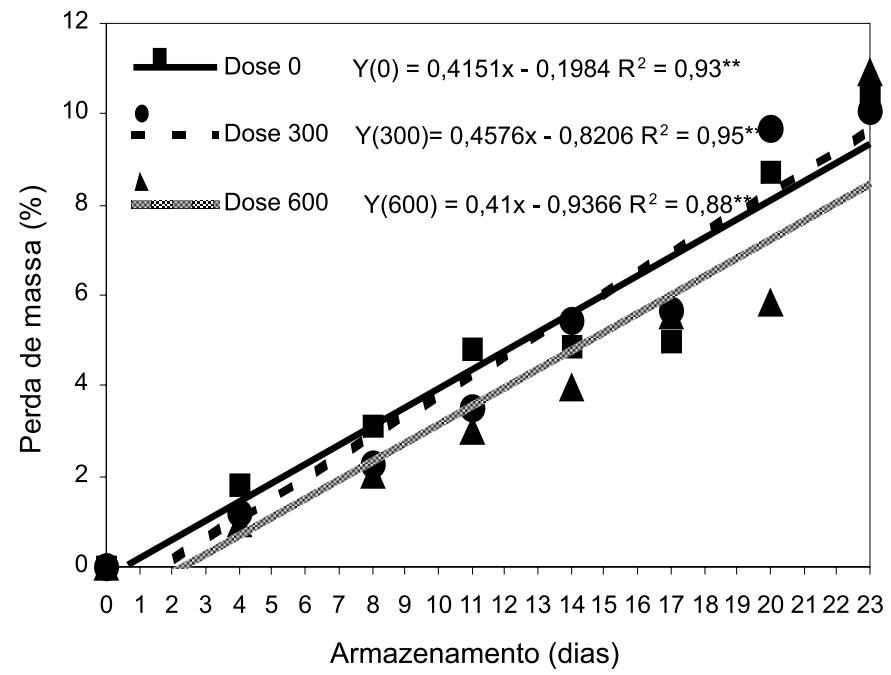

FIGURA 2 - Perda de massa fresca de sapotis após tratamento com $0 ; 300$ e $600 \mathrm{~nL} \mathrm{~L}^{-1}$ de $1-\mathrm{MCP}$ e armazenados a $25^{\circ} \mathrm{C}$ e $70 \%$ UR.

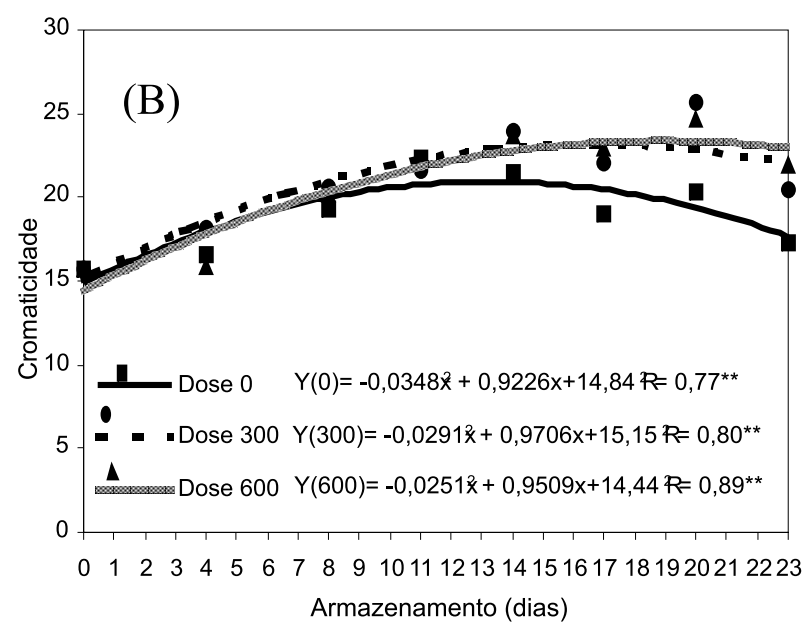

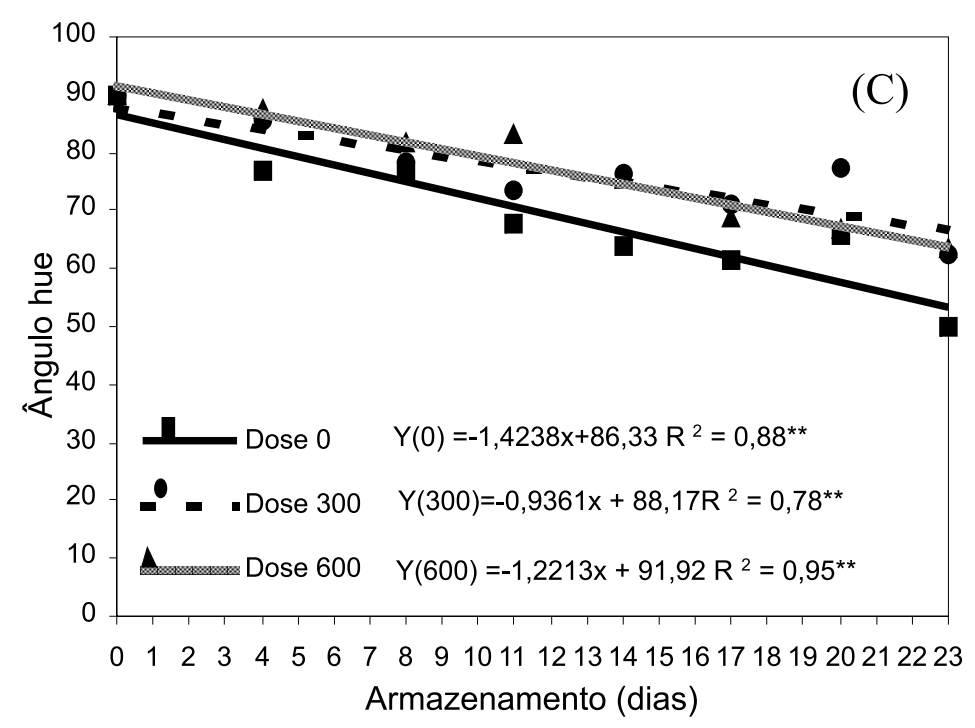

FIGURA 3 - Coloração da polpa de sapotis [L*(A), Cromaticidade (B) e Ângulo hue (C)] após tratamento com 0; 300 e $600 \mathrm{~nL} \mathrm{~L}$-1 de 1-MCP e armazenados a $25^{\circ} \mathrm{C}$ e $70 \%$ UR.

O comportamento dos SS e AST concorda com o observado por Ramadan et al. (1983), de que não existe acúmulo de açúcares em sapoti após a colheita. Entretanto, em outros trabalhos com sapoti, foi verificado um pequeno acréscimo de SS e AST durante o armazenamento (Miranda, 2002). Pathak \& Bhat (1952) sugeriram que, durante o amadurecimento do sapoti, parte da sacarose utilizada para os processos metabólicos é resultado da degradação de constituintes do látex do fruto por microrganismos ou enzimas do próprio látex. Este fato pode ser a razão pela qual os açúcares não diminuíram durante o pico climatérico, em que a atividade respiratória 


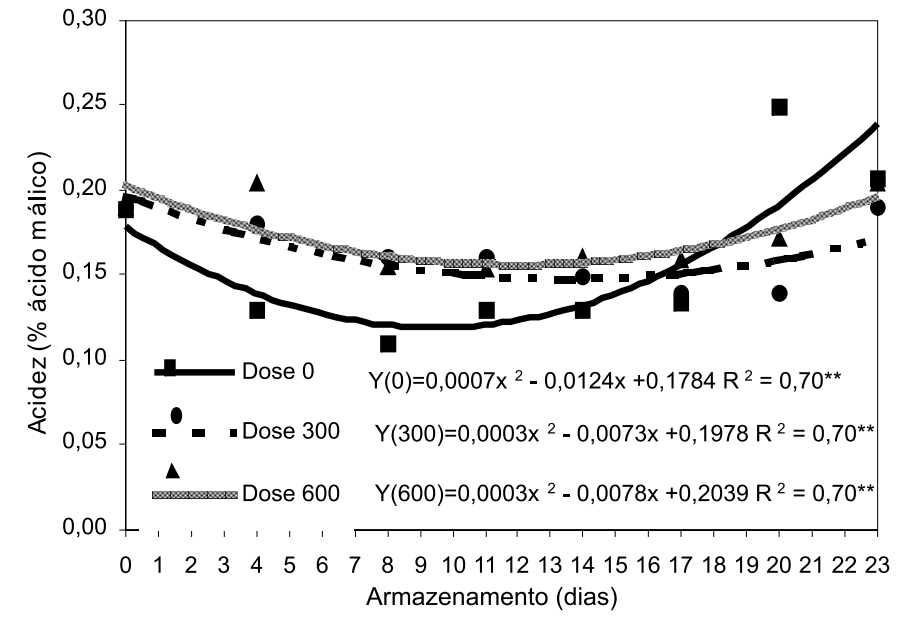

FIGURA 4 - Acidez titulável (\% ácido málico) de sapotis após tratamento com $0 ; 300$ e $600 \mathrm{~nL} \mathrm{~L}^{-1}$ de 1 -MCP e armazenados a $25^{\circ} \mathrm{Ce} 70 \%$ UR.

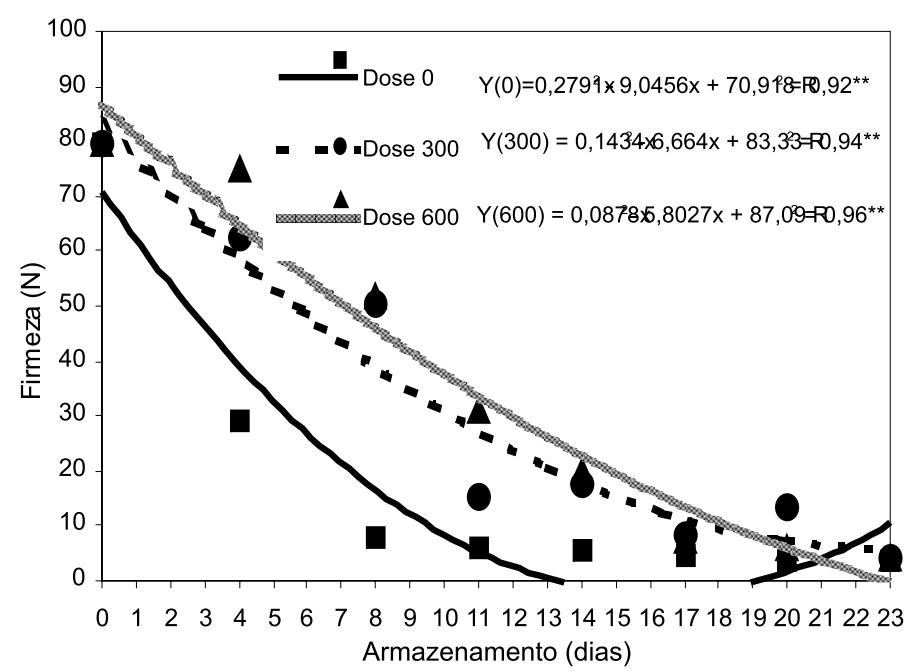

FIGURA 5 - Firmeza de sapotis após tratamento com 0; 300 e 600 $\mathrm{nL} \mathrm{L}{ }^{-1}$ de $1-\mathrm{MCP}$ e armazenados a $25^{\circ} \mathrm{C}$ e $70 \%$ UR.

é alta e necessita de muito substrato.

Ao longo do armazenamento, houve redução intensa na firmeza dos frutos-controle (Figura 5), onde os valores observados para esta variável reduziram de $79,74 \mathrm{~N}$ no dia da colheita para $7,79 \mathrm{~N}$ aos 8 dias de armazenamento. Tais resultados concordam com os de Araújo Neto et al. (2001). Para os frutos tratados com 1-MCP, a redução da firmeza foi retardada. Observou-se um menor amolecimento com a dose de $600 \mathrm{~nL} \cdot \mathrm{L}^{-1}$, embora essa diferença não seja estatisticamente significativa. No final do armazenamento, os frutos tratados com 1-MCP apresentaram amaciamento semelhante ao do controle (Figura 5). Isto indica que novos receptores de etileno foram sintetizados, e as células recuperaram a sensibilidade ao etileno, ocorrendo o amadurecimento do fruto normalmente.

Pinheiro (2004) observou retardo no amaciamento de bananas

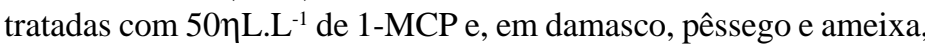
também foi constatada manutenção da firmeza após tratamento com 1-MCP (Lurie \& Weksler, 2004). A hidrólise da parede celular primária e da lamela média é o principal processo responsável pela perda de firmeza dos frutos. Dessa forma, a eficiência do 1-MCP em manter a firmeza pode ser justificada pelo fato de as principais enzimas responsáveis pela hidrólise da parede celular serem ativadas pelo etileno (Majumder \& Mazumdar, 2002).

\section{CONCLUSÕES}

1) O 1-metilciclopropeno (1-MCP) retarda o amadurecimento e prolonga a vida útil pós-colheita de sapoti.

2) A concentração de 300 nL.L. - $^{-1}$ de 1-MCP apresentou melhores resultados prolongando a vida útil pós-colheita do sapoti por seis dias.

\section{REFERÊNCIAS}

ARAUJO-NETO, S.E.; PRACA, E. F; CARVALHO, E.F.; ALVES, R.E; MENEZES, J.B.;

MORAIS, E.A. Determinação do ponto de colheita e índices de maturação para sapoti (Manilkara achras). Revista Brasileira de Fruticultura, Jaboticabal, v.23, n.1, p.45-49, 2001.

AOAC-ASSOCIATION OF OFFICIALANALYTICAL CHEMISTRY. Official methods of analysis of the Association of Official Analytical Chemistry. $17^{\text {th }}$ ed. Washington, 2002. 1115p.

BAEZ, M.A; SILLER, J.H.; HEREDIA, J.B.; PORTILLO, T.; ARAIZA, E.; GARCIA, R.S.; MUY, M.D. Fisiologia poscosecha de frutos de chicozapote (Achras zapota L.) durante condiciones de mercadeo. Proceedings of Interamerican Society of Tropical Horticulture, Florida, v.41, p.209-214, 1997.

BANDEIRA, C.T. et al. O cultivo do sapotizeiro. Fortaleza: EmbrapaCNPAT, 2003. 20p. (Circular Técnica, 13).

COCOZZA, F. D. M. Maturação e conservação de manga 'Tommy Atkins' submetida à aplicação pós-colheita de 1metilciclopropeno. 2003. 175f. Tese (Doutorado em Engenharia Agrícola)-Universidade Estadual de Campinas, Campinas, 2003.

GOLDING, J. B.; SHEARER, D.; WYLLIE, S. G; MCGLASSON, W. B. Application of 1-MCP and propylene to identify ethylenedependent ripening processes in mature banana fruit. Postharvest Biology and Technology, Amsterdam, v.14, n.1, p.8798, 1998. (não consta no texto)

HAMRICK, D. Ethylbloc goes liquid. Grower Talks, Batavia, v.65, 105p. 2001.

INSTITUTO ADOLFO LUTZ. Normas analíticas, métodos químicos e físicos para análise de alimentos. 3.ed. São Paulo, IAL, 1985. v.1, 533p.

JEONG, J.; HUBER, D. J.; SARGENT, S. Influence of 1methycycloproprene (1-MCP) on ripening and cell wall matrix polysaccharides of avocado (Persea americana) fruit. Postharvest Biology and Technology, Amsterdam, v.25, p.241256, 2002.

LURIE, S.; WEKSLER, A. Effects of 1-methylcyclopropene on stone fruits. In: INTERNATIONAL POSTHARVEST SYMPOSIUM, 5., 2004, Verona. Abstracts... Verona: The Italian Postharvest Working Group, 2004. p.5.

MAJUMDER, K.; MAZUMDAR, B. C. Changes of pectic substances in developing fruits of cape-gooseberry (Physalis peruviana L.) in relation to the enzyme activity and evolution of ethylene. Science Horticulturae, Amsterdam, v.96, p.91-101, 2002.

MICKELBART, M.V. Sapodilla: A potential crop For subtropical climates. In: JANICK, J. Progress in new crops. Alexandria: ASHS Press, 1996. p.439-446.

MIRANDA, M.R.A. Alterações fisiológicas e histológicas durante o desenvolvimento, maturação e armazenamento refrigerado do sapoti. 2002. 136f. Tese. (Doutorado em Fitotecnia)Universidade Federal do Ceará, Fortaleza, 2002.

MIRANDA, M.R.A.; SILVA, F.S.; ALVES, R.E.; FILGUEIRAS, H.A.C.; ARAUJO, N.C.C. Armazenamento de dois tipos de sapoti sob condição de ambiente. Revista Brasileira de Fruticultura, Jaboticabal, v.24, p. 644-646, 2002. 
MORAIS, P. L. D. de; LIMA, L. C. O.; ALVES, R. E.; FILGUEIRAS, H. A. C.; ALVES, J. D.; NASCIMENTO, F. E. N. Atividade respiratória e qualidade pós-colheita de sapoti. In: CONGRESSO BRASILEIRO DE FRUTICULTURA, 18., 2004, Florianópolis. Anais... Florianópolis, 2004. CD-ROM.

PATHAK, S.; BHAT, J.V. Studies on the carbohydrate metabolism of Achras zapota L. fruit. Journal of the University of Bombay, London, p.11-20, 1952.

PINHEIRO, A.C.M. Qualidade pós-colheita de banana 'maçã' submetida ao 1-MCP. 2004. 60 f. Dissertação (Mestrado em Ciência dos Alimentos) - Universidade Federal de Lavras, Lavras, 2004.

PORAT, R; WEISS, B.; COHEN, L.; DAUS, A.; GOREN, R.; DROBY, S. Effects of ethylene and 1-Methylcyclopene on the postharvest qualities of 'Shamouti' oranges. Postharvest Biology and Technology, Amsterdam, v.15, n.3, p.155-163, 1999.
RAMADAN, L.; MENDOZA, M.; OSUNA, M.; PANZZA, C. Acumulacion de azucares,perdida de textura y contenido de solidos solubles totales en nispero (Achras sapota) variedad Conchudo. Revista de la Faculdad de Agronomia de la Universidade de Zulia, Venezuela, v.6, n.2, p.744-757, 1983.

SALTVEIT, M.E. Effect of ethylene on quality of fresh fruits and vegetables. Postharvest Biology and Technology, Amsterdam, v.15, p.279-292, 1999.

YEMN, E.W.; WILLIS, A.J. The estimation of carbohydrate in plant extracts by anthrone. The Biochemical Journal, London, v.57, p.508-514, 1954. 